\title{
Bridge between absorbing and absorbed: Ethiopian mediators in the Israeli Public Service
}

\begin{abstract}
Rachel Sharaby
Department of Sociology and Anthropology, Ashqelon Academic College and Social Sciences Department, Bar Ilan University, Hashmonaim St. 2, Petach Tikva 49275, Israel. E-mail: rsharaby@gmail.com. Tel: 972-3-9340075.

Accepted 18December, 2012

This article examines the nature of the work of traditional mediators (Shmaglotz) of immigrants from Ethiopia in Israel, within the framework of municipal mediation centres. These centres are managed by welfare divisions in collaboration with the police and additional public bodies. The findings indicate that the collaboration between the shmaglotz and the professionals serves the absorbers as well as the absorbed. The absorbers are exposed to the culture of the immigrants from Ethiopia and contribute to the institutionalization of the traditional mediation model in a modern society. Nonetheless, the absorbers did not adopt an interactive multicultural approach, and the shmaglotz model is applied solely to the community of immigrants from Ethiopia. For the absorbed, the traditional mediation enables them to preserve values from their culture. However, through the shmaglotz and their old-new toolbox, the immigrants are exposed to dialogue with the culture of the absorbers.
\end{abstract}

Key words: Ethiopia, pluralism, tradition, mediators, immigrants.

\section{INTRODUCTION}

The traditional mediators in Ethiopia are called shmaglotz (elders in Amharic; in the singular - shmagle). They were the elders of the Jewish community and served as an informal judicial institution. The status of the shmaglotz was secondary to that of the religious priests (kessoch) who headed the communities and served as religiousspiritual leaders (Mula-Degai, 2007:70). These two types of leaders fulfilled a role of social control, intended to ensure the conformity of the community to accepted values and norms.

The shmaglotz were respectable and influential people with life experience and wisdom. They were known for their ability to persuade and resolve disputes (Bodowski et al., 1989:5; Naget, 2006:1-2). The shmaglotz resolved disputes in the family and in the community in matters of matrimony, property, capital offenses and in times of need mediated between the community and the regime (Kaplan, 2008:47; Kogan and Mula, 2005:37-38).

This article will discuss shmaglotz who today work in urban mediation centres in Israel. As will be described henceforth, these centres were established in 2003 and are managed by the municipal welfare divisions, in collaboration with the community policemen and additional public bodies.

Since the 1970s, a mediation approach called alternative dispute resolution has become prevalent around the world and in Israel (Shemer and Bar-Guy, 2001). The common model is the pragmatic one, established by Fisher and Ury $(1981,1991)$. The goal of this model is to end the conflict with an immediate agreement, where the mediator focuses on solvable consensus issues. In contradistinction, the transformative mediation model developed by Bush and Folger $(1994,2005)$ does not strive to an immediate end of the controversy, but rather attributes importance to the mediation process itself, which creates a change in the attitudes of the litigants.

Intercultural mediation in the community is a comprehensive practice that deals in the relations between a community of immigrants and the absorbing society and its institutions. The goal of the mediator is to mediate between cultures that represent different ways and viewpoints for achieving the same goal: advancing personal and social welfare in the community (Shemer and Bar-Guy, 2001).

Violence as a social phenomenon has been increasing in Israel in recent decades. In 2003 the Israeli 
government established a committee "for advancing communication, dispute resolution and mediation in the community", with representatives of the ministries of welfare, justice, construction and housing, immigration absorption as well as Joint Israel in order to systematically cope with the problem of violence. In a document published by the committee it announced the development of a comprehensive program whose supergoal is to advance multicultural communication and lead to a more understanding and tolerant society, a society that knows how to handle foci of dispute in an agreedupon and intelligent manner. This strategy was based on values of human dignity, acceptance of the other, intercultural sensitivity, opposition to violence, recognition of social rights and mutual trust (Development of Strategy, 2003).

At the local level the committee emphasised the need for defining action goals at two levels: prevention of disputes by promoting dialogue, acquaintanceship and understanding between different groups of origin or different cultures and resolution of disputes that already broke out, via mediation. It was recommended that municipal mediation centres be established in settlements in which there are large concentrations of new immigrants.

The mediation centres were established in order to reduce the load on the courts by referring litigants to a transformative mediation process which comprises an alternative to the pragmatic mediation process which often exacerbates the dispute, and to resolve disputes among immigrants which exacerbate due to intercultural conflict. In my opinion, both goals indicate a new multicultural legal approach, but also the helplessness of state authorities in resolving disputes in general, and among immigrants in particular.

Mediation centres were established in towns where there is a large concentration of new immigrants. They are managed by the welfare divisions of the local authorities, since it has become clear that a program for the absorption of weak immigrants will be effective if it is incorporated into a division for social services that has an integrative view of local needs. The mediation process is a community-systemic process, which is essential for the success of the immigrant absorption program and is also effective at times of limited resources (Bustin, 2004).

The procedure at the mediation centres is conducted according to the principles of transformative mediation, with the development of dialogue, dignity, agreement and reference to the unique needs of the parties. The procedure emphasises the importance of understanding the cultural codes, and is conducted in different languages.

The members of the administrative team of the mediation centres are social workers and mediators by training, and are responsible for dozens of certified mediators (including shmaglotz) from different ethnic groups. These mediators are volunteers, and this certainly reflects negatively on their status. The state thus activates the shmaglotz to help in the absorption of immigrants, but does not formally recognise them as workers with rights within the governmental mechanism. They are not compensated for their contribution to the community and to the Israeli system. All mediators participate in a course that trains them in the culture of unique groups (Israel and Meir, 2006:12-14) and in mediation models appropriate for their culture, such as the model of the shmaglotz for immigrants from Ethiopia.

Before dealing in this unique major issue, of integrating a traditional custom of immigrants within the absorbing mechanism, I shall review general theoretical viewpoints on the issue of immigration and policy towards immigrants.

\section{IMMIGRATION LITERATURE}

A review of the research literature on immigration indicates a certain change in theoretical perceptions and in the attitude of societies towards immigrants. The theoretical model of the cultural assimilation of ethnic minority groups within the culture of the absorbing society has been awarded extensive attention in immigration literature, mainly until the 1960s. This model viewed the immigrants as a subculture relative to the dominant culture, and assimilation was perceived as a positive process in societies whose dominant ideology supported the idea of a "melting pot", especially in the United States (Huntington, 2004), with the aim of creating a homogeneous national collective.

According to research carried out by Warner and Srole (1945), ethnic minority groups must assimilate into the large surrounding groups except where the existing ethnic groups comprise the majority. In this manner, the majority will not be affected culturally by the minority. Furthermore, these researchers created a model for predicting the time that will be required for different ethnic groups to become assimilated in American life based on an examination of the extent of assimilation versus the extent of preservation of the ethnic tradition.

The well-known sociologist Gordon (1964) also suggested a unidirectional process of assimilation and the disappearance of the immigrant group within the dominant group. In his opinion, two major stages should be differentiated in this process. The first stage is behavioural assimilation: adoption of the external behaviour, dress, language, and economic and everyday habits. The second stage is structural assimilation: entry into social cliques and organizations. In his opinion, the most important sign of assimilation is mixed marriages, which lead to a rejection of the values of the ethnic minority and adoption of the values of the dominant group.

Research on the adjustment of immigrants to the new society was thus characterized by the adoption and 
development of linear models of social change (Sayegh and Lasry, 1993). Brody (1975) claimed that change and the immigrant's social adjustment depend on skills, social relations, expectations and social conditions. A polar perception of assimilation in immigration research was prominent in the attitude towards minority immigrants who originated from countries that were perceived as not modern (Hechter, 1975; Vormeulen and Govers, 1997).

The multicultural model began to develop in the immigration research beginning in the early 1960s. This model refers to a society which is composed of a mosaic of ethno-cultural groups, which preserve their cultural identity and participate in the general national social system. The structural aspect of multiculturalism refers to fairness in the division of power between different cultural groups in society (Sarup, 1986).

The claim that the assimilation policy was not achieved even in societies which aspired towards assimilation, has strengthened in immigration research in the past decades. This is due to the fact that the immigrants are interested in preserving their ethnic identity (Etzioni, 1966/7). Glazer and Moynihan, in their classical research Beyond the Melting Pot $(1963,1970)$ on different ethnic communities in New York, began to doubt the validity of the assimilation model. Their conclusion, which is relevant to the current research, was that ethnicity is still an important driving force in the social reality, since cultural, social and economic differences persist for at least several generations. These researchers claimed that the ethnic identity was not weakened, but rather comprises part of the American reality and is even strengthening and turning into a base for social and political action.

New researches in the field of immigration also view the assimilation process critically. For example, Rumbaut (1997) claimed that in practice, non-linear processes of change appeared in the adjustment of immigrants to the United States, as well as non-satisfaction from assimilation. Furthermore, expressions of ethnic identity, opposition and creative mixing appeared, and not only simple surrender to the dominant centre.

Alba and Nee (2003:1-16), in their research on American society, indicated that since the 1960s assimilation is regarded as negative, as something that casts a cloud on minorities who tried to preserve their lifestyle and culture. However, there was an awakening of the ability to preserve the different and the ethnic as a result of various events around the world which raised awareness of civil rights, and today assimilation has weakened. In their opinion, preservation of the ethnic uniqueness affords advantages to the members of the group and multiculturalism enriches society.

The strength of particular cultures is on the rise today, following the introduction of post-modern thought, and cultural pluralism is promoted. The sociological challenge that faces the multicultural theory is how different communities can exist side by side within one political framework and realize their culture.

Entzinger (2005) examined how liberal democratic societies that formally recognize cultural pluralism accept multiculturalism within the context of immigration. He concluded that different attitudes exist. Nonetheless, he demonstrates that a change has been taking place in recent years in the recognition of immigration and the diversity that is created as a result of immigration. Many countries have begun to emphasise the need for greater unity, and awareness that there are limits to diversity is on the increase. The ongoing immigration is forcing the liberal nation-state to reconsider its inclusion mechanisms, especially for immigrants who come from countries which are not liberal and democratic. Entzinger claims that each society must demand a certain identification with a common core of its members. Beyond that they should be given the freedom to preserve their tradition and relations.

Berry's important ethnographic work, which spanned several decades (for example, 1997, 2004), leads to the conclusion that even if the regime makes different demands of immigrating populations regarding the preservation of their heritage, such as cultural assimilation or integration, the immigrants themselves may respond with alternatives that are not necessarily compatible with the trends of the regime. According to the model which Berry developed, immigrants as individuals and as a group may use four alternative strategyresponse patterns during the intercultural encounter: segregation, assimilation, marginality and integration. Each of the approaches indicates the extent of the immigrants' commitment and identification with the culture of origin on the one hand, and with the culture of the majority on the other hand.

Israel is not exceptional in this aspect, and changes in its policy on immigrant absorption have taken place. In the first decades after its establishment, Israel introduced an assimilative policy that measured the success of absorbing the immigrants by the extent to which they abandoned their culture of origin and resembled the absorbing society (Leshem, 2003). The Israeli 'melting pot' approach was common until the 1970s, but has since then been abandoned. One of the reasons for the abandonment of this policy was that it perpetuated the marginality of the immigrants, created deep social and economic divides, aroused protest movements and harmed social solidarity. It increased the demands of ethnic groups for legitimate integration in the culturalpolitical agenda (Yona, 2005). These outcomes, as well as social and political changes that took place in Israel, advanced a more pluralistic approach to the absorption of immigrants (Spector, 2000).

The change is expressed in the introduction of a policy of inclusion and cultural sensitivity in the absorption of immigrants from the Soviet Union and Ethiopia since the 1990s (Sadan, 2009:59). Training and employing mediators in educational institutions in immigrant settlements 
as well as intercultural mediation in the community which is today accelerating under the encouragement of governmental agencies, illustrate the new policy (Shemer and Bar-Guy, 2001). The new policy is also reflected in the establishment of municipal mediation centres, with participation of shmaglotz, which will be discussed in this study.

\section{The goal: Observe the absorbers and the observed}

In this article the work of the shmaglotz is examined in a new social context - after the immigration of the Jews of Ethiopia to Israel. It focuses on the work of the shmaglotz at the Alon Mediation Centre in a large town in the south of the country, which is the first such centre established in Israel, as well as the largest of its kind and also examine the extent to which the shmaglotz contribute to conflict resolution among members of their community, especially in family matters, and how they may serve as an intercultural bridge that changes cultural norms among immigrants from Ethiopia and in state institutions. A discussion of the work of the shmaglotz and their inclusion in the public service in Israel has great research and practical significance. It will supply an opportunity to focus not only on the absorbed, but also on the absorbing society, and will enable examination of changes that may take place in its attitudes as a result of the entry of immigrants, an issue that has not been illuminated sufficiently in immigration literature.

This study will also enable us to examine the declared multicultural policy of immigrant absorption in Israel, in practice and also examine the multicultural model adopted by the absorbing mechanism when including the shmaglotz in conflict resolution: was it an interactive multiculturalism model where mutual interactions and influences develop between the different cultural groups, or a federative pluralism model where each group maintains its cultural characteristics without any mutual effects (Sever, 2001).

The research method in this article is qualitative, and is based on different pools of people, from whom information is drawn in an in-depth interview throughout 2008 and 2009. One group of interviewees is shmaglotz who work at the municipal mediation centre in the town of Alon. The names of the shmaglotz were obtained from their coordinator at the centre and interviewed; 12 of 14 shmaglotz agreed to be interviewed. All interviewees are men, aged 60 to 80 , who immigrated to Israel in the 1980s and early 1990s and all served as shmaglotz already in Ethiopia and participated in a training course in Israel. The interviews took place in Hebrew: ten were held at community centres of immigrants from Ethiopia and two were held in the homes of the interviewees. Because they immigrated at a rather old age, they speak Hebrew but have difficulty reading and writing in this language.
The community of immigrants from Ethiopia is a closed community, and people do not tend to share their personal matters with others, especially with strangers, as indicated by a famous Amharic saying "things are kept in the stomach". Interviews with them are therefore regarded as an invasion of privacy. Furthermore, the issues brought for mediation are sensitive personally and for the family, especially conflicts between spouses or siblings, between parents and their children or between neighbours. Therefore, the first interviewees were reached through the social workers, and to the shmaglotz as a researcher of immigration and the intercultural encounter between traditional and modern society. After assurance to maintain confidentiality, they opened up and involved other shmaglotz in participating in the interview.

For better cooperation, deep care as a researcher towards the confidentiality of information presented by the shmaglotz as leaders, for the members of their community who are experiencing difficult in absorption crises was emphasised. As a result, the shmaglotz were willing to publicise their work at the mediation centre, with the goal of encouraging members of the community to turn to them and ensure continued use of the traditional mediation model within the public service. However, the mediation process and its effectiveness were presented in their point of view.

In order to provide complete understanding of this issue, another pool of interviewees, professionals from the Israeli public service, who comprise factors outside of the community of immigrants from Ethiopia, were interviewed. And also, the head of the community social work department in the town of Alon and the administrative team of the mediation centre, which included the head Shulamit - who is a community social worker and mediator and has headed the centre since its establishment; Dov - a mediator and general mediation coordinator at the centre; Smadar - a mediator and manager of immigrants' mediation; and Gil - a mediator and coordinator of the group of shmaglotz as well as several community social workers were interviewed. In total, about 20 people were interviews which took place at the offices of the social work department or at the municipal mediation centre. Colourful advertisement sheets in different languages, published by the municipal mediation centre at Alon, afforded extensive information. Standard forms in Amharic with a translation into Hebrew, found at the offices of the shmaglotz, also helped in understanding the process.

The names of the town and people mentioned in the article are fictitious, in order to prevent identification of the litigants and maintain confidentiality.

The article focuses on mediation via the shmaglotz which is offered at urban mediation centres for immigrants from Ethiopia as an alternative for conflict resolution. It also deals on the legal and procedural aspects of the shmaglotz' work, and examine the nature of intercultural mediation which they carry out. 


\section{Shmaglotz at Mediation Centres}

The Jews of Ethiopia immigrated to Israel in two waves: Operation Moses in 1985 and Operation Solomon in 1991 (Spector, 2000; Weil, 2008). The Judaism of the immigrants from Ethiopia was questioned, and they were required to undergo conversion (Corinaldi, 2005; EntebyYemini, 2010). The authority of the religious priests (kessoch) in Israel was undermined, because they were not recognised by the religious establishment and because of the distancing of the youths, who underwent modernization processes (Corinaldi, 1998:191; Weil, 1997). During the 1990s, after a struggle of activists from the Ethiopian community, some of the kessoch were included in the religious establishment in Israel (Kaplan and Salamon, 2004). The leadership crisis also affected the traditional mediators, and their activity was weakened towards the late 1980s (Kogan and Mula, 2005:37-38).

The immigration also disrupted balance in the immigrants' families. The adults lost their status and became dependent on the younger members of the family and on state institutions. The traditional role division became blurred and the status of the men weakened (Minuchin et al., 1997). Opportunities opened for the women, due to a more liberal worldview of the new society and the position of the services system in Israel (such as national security allowance), and they began to acquire an education and work outside the home. These changes led to their becoming more independent in making decisions and managing their lives (Leitman and Weinbaum, 1999). The divorce rate increased, where many were initiated by women, and violence within the family increased (Kaplan and Salamon, 2004; Shabtai and Kassen, 2005).

The interviews and written sources (Ben-Ezer, 1992; Bodovski et al., 1989) indicate that the state authorities, especially the welfare services to which most of the immigrants' problems were directed, found it difficult, already at the early stages of the absorption of the immigrants from Ethiopia, to cope with the outcomes of the immigrants' absorption crises and supply them with the proper services. This was due to lack of understanding which originated from cultural differences, which is explained, among others, by the indirect dialogue common among the Jews of Ethiopia. Out of courtesy and respect, they tend not to turn to a person directly, with a request or with presenting a problem, but rather turn indirectly, using metaphors or familiar sayings. This normative cultural language makes it difficult for the social worker to reach the 'nucleus of truth'.

One of the examples can illustrate this problem (Bodowski et al., 1989:8-9). An adult couple turned to the social worker and announced that "our food and water ran out". The social worker examined their economic situation and the state of their apartment and the water pipes. After mediation by a shmaglotz, it became clear that the couple meant that they wanted to divorce. They expressed this using a familiar metaphor in Amharic, which means: we have run out of the basic things that we share as a couple - food that symbolises the material aspect and water which symbolises the emotional aspect.

The interviewees added that the men often refused to settle a family dispute in court and wanted to solve their problems using the method they knew from Ethiopia. It was therefore decided that shmaglotz would handle these cases with professional accompaniment of the welfare services. After a mediation process via the shmaglotz, the couples reached an agreement.

The interviews indicate that the success of the shmaglotz and the impasse which the welfare authorities reached in their care for the immigrants from Ethiopia led them to include shmaglotz in municipal mediation centres. The caretaking factors understood that due to collision between cultural norms, the Western method does not meet the needs of these immigrants, and the shmaglotz model should be reinforced, while adapting it to Israeli society. This initiative reflects the "cultural competence" approach that evolved in social work mainly due to its helplessness in caring for the immigrants. Today it is clear that a successful welfare program is adapted to the values of the immigrants (Cox and Ephross, 1998, Cox 2001; Swell-Coker, et al., 1985). Integrating elements from their culture and consulting with professionals from their community are therefore important (Bustin, 2004; Padilla, 1997).

Adoption of the traditional mediators by state mechanisms reflects a more pluralistic absorption policy that stems mainly from the understanding of the authorities that they lack the necessary tools and skills for handling the community of immigrants from Ethiopia due to the cultural gap (Naget 2006:19). The publications and interviews indicated that all parties involved in the activation of the shmaglotz model undergo training. Welfare workers and community policemen learn about the cultural characteristics of the Jews of Ethiopia and acquire knowledge on the mediation method of the shmaglotz. Nonetheless, the training program is asymmetric and does not present the professionals with cultural elements of the immigrants from Ethiopia which can be implemented in other contexts.

The process of choosing and training the shmaglotz is performed by a local steering committee composed of representatives of the bodies that run the mediation centre. The criteria for choosing the shmaglotz are similar to those that served for choosing them in Ethiopia (Bodowski et al., 1989:5; Naget, 2006:1-2). These are respectable people, influential in the community, adults (aged at least 50) with experience in conflict resolution. They undergo a training course in management of welfare factors, and acquire knowledge on the lawenforcement system, the care and welfare system, state laws, democracy in Israel, conflict resolution in court, etc.

The shmaglotz reported that their on-the-job training helped them acquire the rules of the new society and 
handle the immigrants' problems, as explained by shmagle Ethnog: "A person who does not understand life in Israel finds it very difficult. Everything is strange, different from what it was in Ethiopia. We help in the manner that was customary in Ethiopia. The course gave us more tools for understanding and becoming familiar with different factors, how they work and how to use them".

\section{FINDINGS}

\section{Tradition and modernity in the mediation process of the Shmaglotz}

The conflict resolution process headed by the shmaglotz is called shimgalena (Bodovski et al., 1989: 5-7; Bodovski et al.,1994; Mula, 2001:26-30). Changes took place in this process in Israel due to its transcription into a new social context. However, similarly to Ethiopia, the process is carried out in several stages that will be described henceforth, and the descriptions will be based on the narratives of the shmaglotz and the professionals. In contradistinction to Ethiopia, the entire mediation process is formal and is documented by the shmaglotz on special forms. The shmaglotz mediate a diversity of conflicts, but devote most of their efforts to conflicts within the family. This article will focus on their work within the framework of the Alon Mediation Centre, which was the first centre established in Israel. The legal and procedural aspects were discussed, and also cultural aspects related to their mediation work were examined.

\section{Stage A: Professionals encourage turning to the shmaglotz}

In the first stage of the mediation process the shmaglotz are approached. Conversations with the team of the Alon Mediation Centre indicated that immigrants from Ethiopia sometimes turn directly to the shmaglotz of their own accord, because these understand their language and cultural codes. Sometimes the shmaglotz initiate a mediation process when they discern a dispute. Many disputes are referred to the shmaglotz by state authorities: the family court, the police - community police division, the centre for the prevention of violence of the welfare division, the municipality absorption centre, the rabbinical court, etc. Most referrals are, however, made by the municipality's community social work department.

In a document published by the mediation centre in 2003 entitled "A traditional mediation mechanism for the Ethiopian community", it was written that the concept behind the decision is the use of traditional and community tools to help the systems dealing in the absorption of these immigrants. The goal of the shmaglotz model is to assist the absorbing state as well as the absorbed:

1. Integration of the traditional intervention method within the modern and Western intervention method, with its adaptation to the new systems of laws and rules.

2. Affording knowledge, tools and skills to the shmaglotz, for cultural mediation and conflict resolution.

3. Helping the immigrant population solve the problem of domestic violence that increased following the immigration crisis.

4. Establishing the status of the shmaglotz within the community and using their rich accumulated experience.

5. Introducing cultural elements and a multicultural approach into systems that handle immigration.

Until about one year ago, the shmaglotz were dispersed in several locations around the town. Today they have office hours three times a week, at the community centre of immigrants from Ethiopia, which is found in an area with a large concentration of immigrants from Ethiopia. According to the head of the mediation centre, separation of the shmaglotz was carried out as a result of sensitivity to the culture of the immigrants from Ethiopia: "The Ethiopians are unique in the secrecy within the community. In their traditional community, everything remains within the community".

The older people prefer to turn to a familiar mediation institution. The shmaglotz complained that only some of the Ethiopian youths turn to them because they aspire to be "like the Israelis" and do not want to use old Ethiopian customs and "lag behind". One shmagle connected the decline in the status of the shmaglotz to the generation gap and said:

"I see that the young today are more stubborn. Everything is different, the clothing, the behaviour, their speech and their attitude towards the community. Often they do not get along with their parents and the parents do not understand them. I as shmagle think that there is less understanding of the children for our role as mediators. Today some express less respect than was customary to give the shmaglotz. This is because they are a different generation, they did not emigrate from Ethiopia, and therefore do not understand as well, or do not want to understand".

The interviewees also explained that most of those referring to the shmaglotz are men, while women prefer to turn to social workers (Bodovski et al., 1989). The unwillingness of the women to turn to the shmaglotz is explained, according to the head of the mediation centre, by the significant change in their status, which leads to conflicts within the family. The head of the mediation centre explained that from her conversations she learned that young women who married an older husband in Ethiopia, as was customary there, feel liberated from the rigid family customs after their immigration to Israel and 
want to divorce.

According to Shulamit, "Ethiopian women see the (cultural) regression regarding their status in the shmaglotz. They think that by turning to the shmaglotz they relinquish their new status, since the shmaglotz will prefer the status of the man (as in Ethiopia). They think that the justice of the shmagle is justice that sides with the men". Shulamit and the workers of the mediation centre often try to persuade Ethiopian women who turn to them for help to use the services of the shmaglotz, since the family dispute will not be resolved without the cooperation of the husbands, who prefer the services of the shmaglotz. Nonetheless, the professional workers care for the rights of the women and tell them that if mediation by the shmaglotz does not succeed, the options of regular mediation at the municipal mediation centre or turning to the court are still open to them.

\section{Stage B: The fire is put out while still small}

In the second stage, the dispute resolution procedure was contrary to the procedure in Ethiopia. The shmaglotz do not have the authority to discuss criminal conflicts, such as rape and murder, which are under the jurisdiction of the police and the court-of-law. So, when immigrants turn to the shmaglotz on such issues, they must transfer their handling to the police and the court. The shmaglotz emphasised that the discretion in their handling is absolute and detailed how this was carried out. First, they deem it important to invite the parties immediately, as in Ethiopia, to prevent exacerbation of the dispute. Shmagle Garma illustrated this symbolically and said "the fire was put out immediately while it was still small".

During the first session the shmaglotz congratulate the litigants on their agreement to resolve the conflict and explain the mediation procedure. When one of the spouses wants to use the services of the shmaglotz, and at his request, the social worker persuades the other party to agree and the social worker is present during the first meeting of the couple with the shmaglotz and if necessary also in additional sessions. As in Ethiopia, the shmaglotz hear the claims of both parties during the first sessions, with an in-depth clarification of the problem. The shmaglotz indicated that they view their role in resolving the dispute by listening to the litigants. In the following sessions each party is interrogated separately. When necessary, the shmaglotz summon additional people involved in the dispute for interrogation. They sometimes go to the home of the litigants in order to investigate the root of the problem.

After the shmaglotz identify the source of the problem, they negotiate between the parties to help them reach an agreement. They use different methods of persuasion, such as allegories and proverbs with a moral, originating from the tradition of the Jews of Ethiopia. They often use stories of heroism, ideals and myths whose goal is to lead the litigants to identify with their heroes, and thus increase their motivation and willingness to move in the direction of a suitable solution. The stories include proverbs with moral, quotes from the bible and from sayings of the forefathers and actions attributes to an ideal figure or to a negative figure. These descriptions enable the litigants to choose a figure for identification and thus to understand the desirable model according to the viewpoint of the shmaglotz (Naget, 2006:37).

In Israel, there exist different options for conflict resolution. Therefore, contrary to the situation in Ethiopia, sometimes only one party turns to the shmaglotz for consultation, and these sessions are very brief. However, in most cases both parties turn to the shmaglotz for mediation, and long sessions take place. From the shmaglotz' quotes it can be learned that use of the traditional method, which affords a long time for each encounter, is effective for resolving disputes in Ethiopia as well as in Israel, since it enables the litigants to voice their feelings, soften their attitudes and internalise the solution suggested by the shmaglotz. Understanding the importance of affording time during mediation is essential, in the shmaglotz' opinion, especially for immigrants from Ethiopia who are characterised by restrained behaviour. The protracted process also reflects the transformative value which the shmaglotz attribute to the mediation process.

Another traditional strategy is the enlistment of the religious priests of the community as well as relatives for resolving disputes, mainly those between spouses (Naget, 2006:39). The involvement of parents was effective, since in Ethiopia married couples were under their authority. The collaboration between family and community factors in Israel demonstrates that the shmaglotz still believe in the effectiveness of a holistic resolution of the dispute, since immigrants from Ethiopia still attribute importance to traditional social structures, such as the extended family and the community.

The shmaglotz painfully speak about the increasing difficulties of the Ethiopian family today: violence, murder and suicide. They explained that the main cause for disputes between partners is the change in the structure of the Ethiopian family in Israel, and especially the changing roles. According to the shmaglotz, the husbands want to control their wives as they did in Ethiopia, which leads to arguments about the management of their finances and about the wife going out to work.

Shmagle Tasima told "Many people turn to us because of problems between the husband and the wife, who cannot manage, where the husband thinks as in Ethiopia and does not give his wife money and manages it all himself, or the husband is jealous and does not allow her to go out to work. Many men think that the women should stay at home as in Ethiopia and not go out to work, but to be housewives. Therefore a problem arises between them and this often leads to divorce". 
The shmaglotz also criticise the Ethiopian women, who in their opinion are influenced by the liberal atmosphere in Israel and hurry to demand a divorce from their husbands, as expressed by shmagle Yalo "I am worried about the situation here in Israel in everything related to marital conciliation. A woman whose husband said a word (of threat) immediately complains to the police, and the police remove the husband from the house without clarifying the situation. This encourages many women to act in this manner".

The shmaglotz indicated that they help the couple, and especially the husband, understand the mentality of the new society and the changes that took place in the family and reach an agreement with them. They claim that handling a crisis between spouses in the modern judicial system in Israel is formal and slow. This leads to the accumulation of great anger and frustration, which in extreme cases lead to murder of the wife. The shmaglotz emphasised the advantage of their work which affords the couple personal attention within a short time, in a language and method that are familiar to them and view their work as: "Holy work, giving service for saving lives among the community".

Shmagle Boruk said "Our mediation gives fruit and prevents many dangers to life and much violence, stress in the family and breaking up of the family which causes families and their children to deteriorate in life and makes it difficult for them to become absorbed in Israel. We therefore try to save these lives and help resolve disputes by mediation and peace". Shmagle Ethnog indicated that "Our goal is for the home to remain intact, not to break up the family. And if there is no choice, then to do this in a proper and nice manner". Shmagle Mangisto said "Our power is in the desire to help and from what we learned from our parents, how to behave and how to explain. We speak with the couple and try to help them see the good there is in the family. We ask: Why don't you make up? And many times we succeed, and then you feel happiness in your heart".

The quotes express the shmaglotz's care and responsibility for preserving the stability of the family in Israel. Their understanding, together with criticism of all parties: the men, the women and the judicial system in Israel, position the shmaglotz as a cultural factor that is found in the middle: they draw from tradition but also recognise the more egalitarian laws and values of the new society.

\section{Stage C: They should at least divorce in peace}

In the third stage the shmaglotz formulate a mediation agreement with the consent of the parties. Shmaglotz indicated that most disputes referred to them are resolved, and this is reinforced by testimonies of workers in the municipal mediation centres. When mediation between spouses fails, the shmaglotz try to reach an agreement on how to divide the property and alimony payments, with the help of the couple's parents. The shmaglotz consider it important to help the couple separate out of agreement, mutual respect and by a short procedure, as explained by shmagle Samo: "The goal of the shmaglotz in cases where matrimonial reconciliation cannot be achieved is that they should at least divorce in peace. When they separate by agreement and in peace we prevent disasters (violence and murder). This also saves the couple from going to lawyers. The file is closed. Our mediation led to a significant shortening of the discussions in the rabbinical court".

\section{Stage D: Upholding the agreement}

From the interviewees it can be concluded that only in rare cases was the agreement reached with the Shmaglotz breached in Ethiopia (for example, in a case where the shmaglotz asked the injured party to relinquish on a fine they levied on the injuring party, in order to prevent hostility between the parties, but this party did not agree). The verdicts of the shmaglotz were valid in Ethiopia since members of the community feared social sanctions, and the verdicts of the shmaglotz were also accepted by the regime and the courts (Kaplan, 2008:47). In Israel, the shmaglotz are greatly honoured in their community, but they have lost their status and power, and fewer obey their decisions than in the past.

One explanation for this change stems from a decline in the sense of belonging and commitment of the young Ethiopians towards their community (as also seen from the description of Stage A of the mediation process through the shmaglotz). This is due to the desire of the youths, who were educated in the Israeli education system and who served in the Israeli army, to become integrated within the Israeli society. Furthermore, changes have taken place in the immigrant families. As mentioned, the Ethiopian family underwent changes and shocks following the immigration to Israel. The children and the children's mother adapted rapidly to the new life, whereas the father lost of his authority. Due to the crisis of immigration, the traditional leadership also lost of its status, and the sensitive relations between members of the community and their leadership was usurped (Sharon, 2012:64).

Another explanation is the low status of the shmaglotz in light of the patronising attitude of the Israeli system. Furthermore, they are not an independent judicial body, and their agreements are subject to confirmation by state authorities.

\section{CONCLUSIONS}

This article discusses shmaglotz who work today in urban mediation centres in Israel. These centres were established in 2003 and are run by the municipal welfare 
divisions, in collaboration with the community policemen and additional public bodies. The article supplies us with an opportunity to turn the spotlight not only on the absorbed, but also on the absorbing society itself, and to examine changes that may take place in its attitudes as a result of the entry of immigrants, an issue that has not been sufficiently described in the research literature that discusses immigration. The discussion on the inclusion of the shmaglotz in the public sector in Israel will also enable us, in practice, to examine the declared multicultural policy of immigrant absorption.

A famous Ethiopian saying says that "You should plough the weeds of the country with an ox from that country". This means that problems should be handled with the appropriate tools. According to this saying, the shmaglotz are the most appropriate tool for handling conflicts within their community, since they speak the language of the immigrants, are familiar with their cultural background and work with familiar methods. Out of recognition of these advantages, they are included in municipal mediation centres that operate within the welfare divisions, with collaboration of the police and other bodies.

From this study, which focused on the work of the shmaglotz, I conclude that the collaboration formed between the community policemen and social workers serves both the absorbers and the absorbed. A good mediator should be found in the right place, be accepted by both parties and know enough about both cultures (McLeod, 1981), and the shmaglotz fulfil these conditions rather successfully.

In terms of the absorbers, the joint work patterns with the shmaglotz that were formulated in the mediation centres (for example the presence of a social worker in one or more meetings of the shmaglotz with the litigating parties) and the training undergone by the professionals contributed to their exposure to the culture of the immigrants from Ethiopia. Furthermore, the public service professionals developed an awareness of the importance of the shmaglotz in resolving conflicts. The government's initiative to include shmaglotz in its mechanisms reflects the adoption of a more pluralistic outlook which originates mainly from its helplessness in the absorption of the immigrants from Ethiopia, due to cultural differences.

However, it was concluded that the multicultural approach which is expressed in the inclusion of the shmaglotz is not interactive, but is closer to the federative approach (Sever, 2001), since the shmaglotz model has remained a unique model of mediation intended solely for the specific community of immigrants from Ethiopia. In terms of the absorbers, the goal in the adoption of the shmaglotz was functional. They did not view the shmaglotz as equal partners from whom they can learn and did not internalize values and knowledge from them which could serve them in their work with other communities (for example, adopting taking a long time for each meeting).
The federative multicultural approach is clearly apparent from the sayings of Shulamit, the head of the mediation centre: "Today we enable cultural codes to influence the conduct of the dispute. Integration may lead to success. The shmaglotz also change our approaches. There is mediation, arbitration, the court, and there is also the way of the shmaglotz. We reserve this model for the Ethiopian community. Based on this research, viewpoint as the absorber has changed: "Before I thought that everyone should be like me, but now I accept the difference as an equal, and that is a multicultural approach".

Thus, recognition of the importance of the shmaglotz increased among the welfare and law enforcement authorities and they even encourage the immigrants to turn to them. The state authorities thus contribute to the (particular) continuity and institutionalization of traditional mediation within the mechanisms of the absorbing society and to its strengthening among the immigrant community. In terms of the absorbed this means that the state enables them to maintain values from their culture of origin, which help them in the absorption process. Nonetheless, the immigrants are exposed to dialogue with the culture of the absorbers, and new cultural characteristics are added to their identity, such as awareness of values and laws in Israel. The shmaglotz, who in Ethiopia served as legal mediators but in Israel serve also as intercultural mediators, help the dialogue on their identity. Their advantage is in their new toolbox (Swidler, 1986), which contains experience, knowledge and traditional methods (for example, immediate care, use of proverbs, transformative mediation, long time for discussion and involvement of parents and spiritual leaders), but also modern knowledge, means and tools which they received from the professionals (for example, knowledge of the state laws, familiarity with the caregiving systems, managing a formal mediation process and team work with government bodies).

The connected vessels show that syncretism is created in the mediation model of the shmaglotz and in their identity, meaning a mixing of different traditions and the creation of a new cultural tradition (Stewart and Shaw, 1994:1-26). Syncretism may indicate a process of change in the personal and the group identity, as well as the configurations of this process (Leopold and Jensen, 2004b). It comprises part of the negotiation between identities under different situations, including immigration. Syncretism can take place by choice, consciously, but often develops unintentionally (Leopold and Jensen, 2004a:3). It involves processing, interpretation and adaptation of traditional symbols and customs to the new culture, with adoption of foreign contents. Thus, variations of tradition and modernity are created among minority groups (Shils, 1981:240-246).

The present study shows that the old-new model of mediation helps the shmaglotz to effectively handle new occurrences of conflict which stem from the immigration. 


\section{Acknowledgements}

This research was supported by the Research Committee of the Ashkelon Academic College, Israel.

\section{REFERENCES}

Alba R, Nee V (2003). Remaking the American Mainstream. Harvard University Press, Cambridge and London.

Ben-Ezer G (1992). Like Light in a Vase. Reuben Mas, Jerusalem (Hebrew)

Berry J (2004). From a melting pot to multiculturalism: Implications for the higher education system and for training welfare and education workers. In E Leshem and D Ruar-Striar (eds), Cultural Diversity as a Challenge for Human Services. Magnes, Jerusalem, pp. 114-125 (Hebrew).

Berry JW (1997). Immigration acculturation and adaptation. Applied Psychology: Int. Rev. 46:5-68.

Bodovski D, Joseph D, Eran Y, Rosen H (1994). The Jews of Ethiopia in an Intercultural Transition. Betahachin, Jerusalem (Hebrew).

Bodovski D, Joseph D, Eran Y, Rosen H (1989). Issues on the Subject of the Family of the Jews of Ethiopia. Betahachin, Jerusalem (Hebrew).

Brody EB (1975). Migration and adaptation: the nature of the problem. In EB Brody (ed), Behavior in New Environments: Adaptation of Migrant Populations. Sage, Beverly Hills CA, pp. 13-21.

Bush R, Folger J (1994, 2005). The Promise of Mediation. Jossey-Bass, San Francisco.

Bustin E (2004). To Exploit the Opportunities of the Welfare and Immigration Absorption System. Joint Israel and the Ministry of Labour and Welfare, Jerusalem (Hebrew).

Corinaldi M (1998). Jewish Identity: The Case of Ethiopian Jewry. Jerusalem, Reuben Mas.

Corinaldi M (2005). Ethiopian Jewry. Reuben Mas, Jerusalem (Hebrew).

Cox AL (2001). "BSW students favor strengths/empowerment-based generalist practice". Fam. Soc. 82(3):305-313.

Cox CB, Ephross PH (1998). Ethnicity and Social Work Practice. Oxford University Press, New York.

Development of Strategy for Advancement of Negotiation, Conflict Resolution and Mediation in the Community (2003). The National Committee for Advancement of Negotiation, Conflict Resolution and Mediation in the Community, Jerusalem.

Enteby-Yemini L (2010). On the margins of visibility: Ethiopian immigrants in Israel. In T Lomsky-Feder and T Rapoport (eds), Visibility in Immigration. Van Leer Institute and Hakibbutz Hameuchad, Jerusalem, pp. 43-68 (Hebrew).

Entzinger H (2005). Multiculturalism revised. In E Ben-Rafael and $Y$ Sternberg (eds), Comparing Modernities: Pluralism Versus Homogeneity. Brill, Boston, pp. 191-204.

Etzioni A (1966/7). The community of communities. Responsive Community $7(1): 21-32$.

Fisher R, William U (1981, 1991). Getting to Yes: Negotiation Agreement Without Giving In. Mifflin, Houghton.

Glazer N, Moynihan D (1963, 1970). Beyond the Melting Pot: The Negroes, Puerto Ricans, Jews, Italians, and Irish of New York City. MIT Press, Cambridge, MA.

Gordon MM (1964). Assimilation in American Life. Oxford University Press, New York.

Hechter M (1975). Internal Colonialism: The Celtic Fringe in British National Development. University of California Press, Berkeley and Los Angeles.

Huntington SP (2004). Who are We? The Challenges to American's National Identity. Simon and Schuster, New York.

Israel A, Meir Z (2006). The Israeli Police. The Division for Community Policing, Jerusalem (Hebrew)

Kaplan S (2008). Organization of the community. In H Salamon (ed), Ethiopia. Ben-Zvi Institute, Jerusalem, pp. 43-54 (Hebrew).

Kaplan S, Salamon H (2004). Ethiopian Jews in Israel: A Part of the people or apart from the people? In U Rebhun and C Waxman (eds)
Jews in Israel. Brandeis University Press, Hanover and London, pp. 118-150.

Kogan R, Mula D (2005). Community Policing for the New Immigrant Population. The Division for Community Policing, Jerusalem (Hebrew).

Leitman E, Weinbaum E (1999). "Israeli women of Ethiopian decent The strengths, conflicts and successes". In: Parfitt T \& Trevisan E (eds.). The Beta Israel in Ethiopia and Israel. Richmond: Curzon pp.128136.

Leopold AM, Jensen JS (2004a). General introduction. In AM Leopold and JS Jensen (eds), Syncretism in Religion. Routledge, New York, pp. 2-12.

Leopold, AM, Jensen JS (2004b). Religions in contact: power syncretism and creolization: Introduction to Part IV. In AM Leopold and JS Jensen (eds), Syncretism in Religion. Routledge, New York, pp. $142-159$.

Leshem E (2003). Israel as a multicultural state at the opening of the twenty-first century. In in E Leshem and D Roar-Streiter (eds), Cultural Difference as a Challenge to Human Services. Magnes, Jerusalem, pp. 13-111 (Hebrew)

McLeod B (1981). The mediating person and cultural identity. In S Bochner (ed), The Mediating Person. Schenkman, Cambridge MA pp. 37-52.

Minuchin-Izikson S, Hischfeld R, Hanegbi R, Karsilovski D (1997). Family roles among immigrants from Ethiopia: Change and coping. In E Amir, A Zehavi and R Fargai (eds), One Root Many Branches. Magnes, Jerusalem, pp. 67-98 (Hebrew).

Mula D (2001). The "Shmaglotz" Model - Integration of the Sages of the Ethiopian Community for Resolving Conflicts in the Community and in the Family. The Division for Implementation of Community Policing, Lod (Hebrew).

Mula-Degai I (2007). The Way Home. Self-publication, Rehovot (Hebrew)

Naget $Y$ (2006). The Perception and Understanding of Members of the Shmaglotz Institution of How They Intervene in Processes of Conflict Management among the Community of Immigrants from Ethiopia. MA Thesis, Bar-llan University (Hebrew).

Padilla YC (1997). Immigrant policy: Issues for social work practice. Soc. Work 42(6):595-606.

Rumbaut RG (1997). Assimilation and its discontents: between rhetoric and reality. Int. Migr. Rev. 31(4):923-960.

Sadan E (2009). Community Work. Hakibbutz Hameuchad, Benei Berak (Hebrew).

Sarup M (1986). The Politics of Multicultural Education. Routledge and Kegan Paul, London.

Sayegh L, Lasry JC (1993). Immigrants adaptation in Canada: Assimilation acculturation and orthogonal culture identification. Can Psychol. 34:98-109.

Sever R (2001). Assimilating or interweaving? A conceptual framework for examining the issue of multiculturalism. Gadish 7:45-54 (Hebrew).

Shabtai M, Kassen L (2005). Introduction. In M Shabtai and L Kassen (eds), Moloalem: Women and Girls from Ethiopia. Lashon Zecha, TelAviv, pp. 7-15 (Hebrew).

Sharon S (2012). From Sinai to Ethiopia. Yediot Aharonot, Tel-Aviv (Hebrew).

Shemer O, Bar-Guy E (2001). Intercultural mediation in the community. Mifgash Leavoda Chinuchit-Socialit 14:163-190 (Hebrew).

Shils E (1981). Tradition. University of Chicago Press, Chicago.

Spector G (2000). Some reflections on cultural mediation. Education 6:155-162 (Hebrew).

Stewart C, Shaw R (eds) (1994). Syncretism / Anti Syncretism. Routledge, London.

Swell-Coker B, Hamilton-Collins J, Fein Sewell E (1985). Social work practice with West Indian immigrants. Social Casework 66:563-568.

Swidler A (1986). Culture in action: Symbols and strategies. Am. Sociol. Rev. 51(2):273-286

Vormeulen H, Govers C (1997). From political mobilization to the politics of consciousness. In C Govers and $\mathrm{H}$ Vormeulen (eds), The Politics of Ethnic Consciousness. Macmillan and St. Martin's, Houndmills and New York, pp. 1-30.

Warner LW, Srole L (1945). The Social Systems of American Ethnic Groups. Yankee City Series, vol. 3, Yale University Press, New Haven. 
Weil S ( 2008). "Zionism and immigration to Israel. In: Salamon H (ed). Ethiopia Jerusalem: Ben-Zvi Institute pp.187-200. (Hebrew).

Weil S (1997). Changing of the guards: Leadership among Ethiopian Jews in Israel. J. Soc. Stud. 1(4):301-307.
Yona Y (2005). Towards multiculturalism in Israel: Spatial aspects. In $R$ Kalush and T Hatuka (eds), Architectural Culture. Rasling, Tel-Aviv, pp. 137-176 (Hebrew). 